\title{
Non-Native Raters and Native Speech: Other Perspective for the Research on Comprehensibility of Second Language Input
}

\author{
Sandra Figueiredo ${ }^{1, *}$, Edlia Simões ${ }^{2}$, Margarida Alves Martins $^{3}$ and \\ Carlos Fernandes da Silva ${ }^{4}$
}

\author{
${ }^{1}$ Department of Psychology, Universidade Autónoma de Lisboa, Lisbon, Portugal \\ ${ }^{2}$ Assistant Professor of Psychology and Education, University of Saint Joseph, Macao, China \\ ${ }^{3}$ Full Professor of ISPA - Instituto Universitário, Lisbon, Portugal \\ ${ }^{4}$ Full Professor of Department of Education and Psychology of University of Aveiro, Portugal
}

\begin{abstract}
This study examines how specific variables such as age, first language, nationality, school grade and socioeconomic status (SES) affect the comprehensibility of second language (L2) speech in 92 second/non-native language learners. Comprehensibility refers to the degree of speech understanding. Fluency, rhythm, grammatical features and word stressing are concurrent factors for the listening comprehension (and the listener comprehensibility) mainly in L2 context. Research evidence focused the quality and differences of speech samples produced by the L2 learners and the comprehensibility rated by native speakers. In reverse scenario there is less evidence on the judgment of $L 2$ learners for speech samples produced by native speakers. In this study we analysed if the comprehensibility ability of 92 young Portuguese L2 learners differ in the following conditions: age, nationality, home language, school grade, proficiency and socioeconomic status. Speech (one text) was recorded by a native speaker and was judged by L2 speakers using 1-5 Likert scale for comprehension difficulty. Main results showed that neither age nor home language had influence for comprehensibility, but socioeconomic, nationality and grades accounted for statistical differences between the groups tested. Also, data suggested that phonetic features are more likely important for the beginner in second language learning compared to the semantic features of speech that heavily depend on vocabulary domain.
\end{abstract}

Keywords: Speech comprehensibility, nationality, grades, socioeconomic status, second language.

\section{INTRODUCTION}

The second language (L2) speech has been researched in several perspectives to understand how individuals develop a bilingual competence or an incomplete bilingual mode (second language proficiency not fully attained). The ease of understanding concerning the non-native speech has been widely focused by using the comprehensibility and accentedness concepts. Comprehensibility refers to the degree in which one understands and processes speech. That processing is facilitated when the accent features (mainly non-native accent) appeared as less evident [1]. But other factors were found concurrent for the comprehensibility of speech such as the word stress, rate, prosody and rhythm. These factors are strongly explained by the personal characteristics of the speaker (native or non-native). Comprehensibility is frequently examined along with the intelligibility and accentedness. In the present study our concern is the comprehensibility analysis, despite of being strongly related to the accented speech.

Since the eighties authors such Gynan [2] and Ensz [3] studied, divergently, the influence of phonology or of

*Address correspondence to this author at the Department of Psychology, Universidade Autónoma de Lisboa, Lisbon, Portugal; Tel: 213177600;

E-mail: sandradfigueiredo@ua.pt grammatical errors to explain comprehensibility. In the same decade, the concept of comprehensibility appeared through the concept of 'comprehensible input' [4] as a result of critical perspective on the Krashen's hypothesis about the L2 understanding and the input quality for accurate learning. Gass and Varonis [5] discussed the importance of 'familiarity' (considering the content or considering the target language) that native listener (and decoder) presents toward a non-native speech. In the nineties, comprehensibility maintained its focus on L2 speech research. Sadoski, Goetz and Fritz [6] developed specific research in order to understand the role of concrete information embedded within the texts as an advantage to turn them more comprehensible. Derwing and Munro [7] and Derwing, Munro and Thomson [8] have devoted their studies to test the correlation between comprehensibility, accentedness and intelligibility. More recently Kennedy and Trofimovich [9] and Trofimovich and Isaacs [10] analysed the impact of semantic cues, lexical richness and grammatical features for the comprehensibility of nonnative speech.

Despite of consistent studies about comprehensibility of L2 speech in the perspective of the native listener, there is less evidence on the other perspective: to estimate the ease of understanding in 
unfamiliar speech (native speech that corresponds to the second language of the listener) but considering the perception of non-native listener. Recent studies in the reverse scenario [11] showed incongruence in their conclusions. They concluded dissimilarities across groups (non-native speakers) that judge differently but the home language (L1) as a factor is not consensual. On the other hand, differences between groups in judging unfamiliar languages might be explained by intrinsic characteristics of the speech itself [11]. In the present study we intend to explore how immigrant students' judge differently for a native speech that matches with their second language; to provide more evidence for this specific field in order to understand which factors determine the listeners' comprehensibility specifically the L2 listeners; and to inform educational practitioners on the instruction of a diversity reference for phonetic in a second language.

\section{METHODOLOGY}

\section{Experiment}

Immigrant' students are expected to judge differently in second language speech comprehensibility.

Task.

a) Listen to the text in Portuguese language:

(Click here to play the text)

Then evaluate how do find this text. Be aware that $1=$ very diffcult to understand and $5=$ very easy to understand.

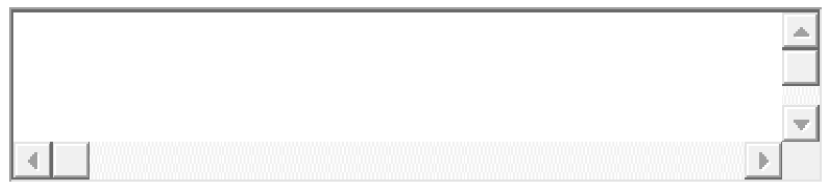

Participants (N92) completed one task comprehensibility task - focusing on the speech characteristics. For this trial, one piece of recorded speech was presented in computer format (audio): firstly, the participants listened one text that was encoded with different accent features in Portuguese language (with accent from the North of Portugal vs. South). Participants received instruction to evaluate the comprehension difficulty of a L2 text completing a Likert-type scale ranging from 1 (very difficult to understand) to 5 (very easy to understand). The piece of text was recorded from a female Portuguese native speaker from the North of Portugal. Several words were strongly accented differently from the accents of regions from the Center and South of Portugal. All participants live in the region of Center/South of the country. The speech sample in order to be evaluated was controlled for a normal speed considering that lower speed in speech generally leads to an identification of 'more accented speech' according to past studies [12-14]. Also there are no grammatical errors intentionally recorded as well as no phonetic errors to avoid biases in the comprehensibility judgment. All the distractors are intentionally presented as supra-segmental features of speech by using prosody and rhythm characteristics of a north dialect. Supra-segmental features are commonly an obstacle for comprehensibility tasks [15]. Along with these tasks, other 14 measures were administered to the same participants and they were told that they were completing a battery of tests to assess language proficiency and cognitive differences among immigrant groups.

Age, nationality, proficiency levels, time of residence, $\mathrm{L} 1$ and school grade were the independent variables for this study. The data collection took place during the years 2013-2015. Age: between 7 and 17 years old $(M=13 ; S D=2,7)$; grades: $K-12$, schools of Metropolitan Lisbon; time of residence: $61 \%$ immigrated in the most recent period evaluated (2014); nationality: Occidental Europe, Least Europe, Indian Asia, China, Africa and South America. The SES was also included as independent variables and was computed by estimating the parents' education and professional/employment situation.

The researcher is a Portuguese native speaker whom rated the speech sample as well as the responses of participants on comprehensibility. SPSS (v. 23) was used to carry out statistical analyses for the experiment testing.

\section{RESULTS}

The data from the task administered to the 92 participants was firstly submitted to a test of homogeneity of variance (Levene's Test) to determine the use of parametric or non-parametric tests. The comprehensibility task was assumed as the dependent variable. Age, nationality, L1, proficiency, school year, home language and SES were tested as independent variables. Attending to the lack of homogeneity for variance of sample $(p<.05)$, the non-parametric test Kruskal-Wallis for independent samples was performed 
to analyze the differences between groups on the comprehensibility test.

For the age variable, no significant differences $(p<$ .05) were detected. The individuals did not vary in a significant way for comprehensibility according to age. The nationality revealed to have influence at a significant level $(p=.045)$. Learners from China presented more difficulty followed by the individuals from Least Europe. Contrasting, groups from Occidental Europe (such as Germany and France) and from Africa (from countries with the Portuguese as Official Language but mainly represented by creoles) showed higher medians for the comprehensibility judgment.

For the proficiency level as well for the home language, no differences were observed. On the other hand, for school year variable the groups did differ significantly $(p=.012)$ : the lower school levels (1st-6th grade) showed to have more difficulty compared to the upper levels (including high school). For the socioeconomic condition as variable, children from unemployed families followed by the children with parents in non-specialized jobs struggle more evidently $(p=.008)$ in comprehensibility compared to the children from families with specialized jobs. The Figure 1 illustrates the performance per group according to the significant scores only.

\section{DISCUSSION}

The experiment confirmed that the immigrant' students effectively judge in different manner the comprehensibility of L2 speech. Previous evidence [1618] determined that first language experience of listeners have influence for the comprehensibility of their own L2 speech. However for the reverse experiment - L2 listeners evaluating the comprehensibility of native speech - there is no differences among language groups considering the judgment of comprehension. These results are consistent with the findings from the study of Kennedy and Trofimovich [9] that did not observed significant differences for the $\mathrm{L} 1$ amount as an effect of comprehensibility in L2 learners. On the other hand,
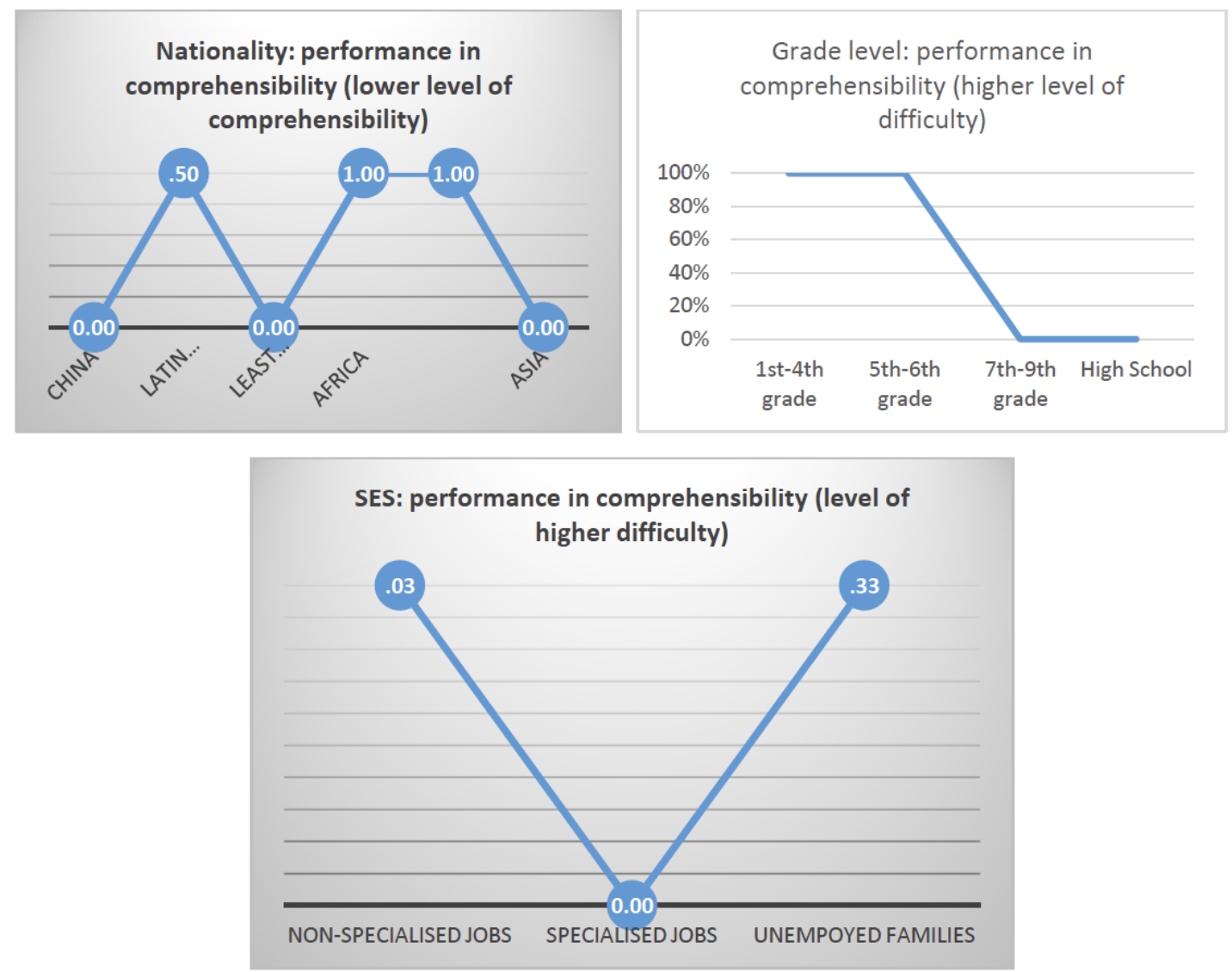

Figure 1: Performance for the comprehensibility considering each group determined by nationality, school grades and SES.

Note: the interpretation of scores should be according to the level of comprehensibility in the scale (for example, the first graphic refers to the level 5 of the comprehensibility scale = "very easy to understand", different for the other graphics). 
studies reported that the amount of exposure to the $\mathrm{L} 2$ and not necessarily the home language explains the advantage for the comprehensibility of speech samples recorded from L2 learners [8]. Additionally, and considering that we have a comprehensibility analysis in a different manner -Portuguese L2 listeners that are raters of speech of native speaker of Portuguese - we have controlled the effect of the inherent preference that raters commonly showed toward a specific L2 accent when that $L 2$ corresponds to the raters native language [19].

In the present study other important factors emerged to understand differences for native speech comprehension in the L2 listeners. Children from China and Least European countries (Ukraine and Russia) showed to struggle more than other nationalities during comprehensibility task. Considering the principle that nationality is implicitly connected to a native language (s), we advance that Chinese children (Mandarin speakers) have less advantage to process the rhythm of sentences in L2 with distant orthography (orthographies with alphabetic systems like the Portuguese case) from their L1 as maintained by Crowther, Trofimovich, Isaacs et al. [16] and by Ferragne and Pellegrino [20]. Duration of vowels would be the main obstacle for these children against Occidental Europeans and African countries that showed in our trial study higher medians for the best levels (less difficulty declared) of comprehensibility. Other studies explored the role of instructed positive attitudes toward accented speech (in other language L2 situation) and had concluded that more instructed individuals in accented speech (Vietnamese accent in English as L2) revealed to have more acceptation toward interaction with English L2 learners [21]. According to this, we suggest that ethnicity could have influence and benefit from instructed awareness on accented speech of others (also including native accent in speech - the dialects) to have more gains for improving comprehension.

Regarding the age factor, no significant influence accounted for L2 listeners' comprehensibility. However groups determined by grades did differ significantly for judgment of text understanding. The lowest grades (K6) compared to the 7-12 (school levels) understood worse the listened stimulus. It is well known that children are more accurate to recall and summarize events after a text listened when compared to adults that exhibit a comprehension decline for this specific skill [22]. In this case younger students did not show supremacy for the comprehension task. A first argument could be advanced here: prior schooling might be argued as a blocking effect for the individuals of this sample that had received schooling in their countries of origin. Prior schooling is greatly involved in differences accounted for immigrant groups and should be addressed in further research as personal characteristics beyond the other characteristics that are advanced to understand the listening skill [23], specifically comprehensibility.

As a second argument: in the first years of school the youngest learners (not necessarily the oldest learners are placed in the advanced grades in the host school) are exposed to one teacher's speech as unique reference for phonetic encoding. Teacher's speech style is the phonetic model for young students [24]. Differently, in the more advanced grades more teachers instruct them and a diversity of linguistic input occurs. Teachers are originally from different regions of the country and that implies phonetic accent diversity. L2 learners could benefit from a more diverse speech daily presented at school (the teachers' speech and their different speech accent) to reinforce a reference for comprehensibility. This could also reinforce their noticing behaviour toward L2 input in order to demand a "comprehensible output" [25]. A third argument: the existent rapid period for phonetic learning [17] in the first years of life might not be explaining why the youngest learners have mastery for different phonetic features in decoding, but on the other hand contribute to explain how children produce nativelike discourse (accent) contrary to their competency to understand multiple phonetic features (the dialect in second language, produced by a native speaker). These data are congruent to other systematic research [26] that discovered that a specific sample of native speakers developed language in the first years of life in a reverse order expected for the development stages of first language (s) acquisition where comprehension precedes the production ability [27-28]. However Werker and Byers-Heinlein [28] concluded that monolinguals and bilinguals are different in language development and the processes of production and comprehension could be more overlapped stages than expected for a bilingual brain.

In the present study proficiency did not emerge as an influent variable according to previous evidence [7] that also did not found predictive value of the language proficiency for the comprehensibility. On the other hand, Saito, Webb, Trofimovich et al. [29] recently determined that beginners in L2 are expected to have difficulty with speech decoding (in L2) compared to the 
intermediate learners. Further research should test this principle in larger samples because one limitation of our study is related to the small number of learners who were effectively assessed by school to identify a proficiency level. Additionally, effects of instruction should be revisited in order to understand the weaknesses for the L2 learners [30]. The SES variable showed to have influence for comprehensibility in these L2 learners, as shown in the children with unemployed parents, which were in the lowest position. Sociolinguistics studies [31-33] developed evidence to support that social environment and status influence the L2 listening abilities. According to those studies, the status and environment determined that monolingual speakers from middle to high classes (in terms of SES) are expected to have different outcomes for language. Language deficit in second language learners associated to low-income families correlated higher with deficit for oral comprehension skills. Additionally lower-SES appears to predict problems for receptive and production skills considering the low vocabulary received at home. On the other hand SES as a factor for the language differences among children could be highly mediated by the phonological sensitivity in the preschool children considering its importance for word and comprehension development [34]. Considering that comprehensibility is different from listening comprehension, we found no knowledge of studies on the correlation between SES and the comprehensibility in the L2 context.

\section{ACKNOWLEDGEMENT}

Foundation for Science and Technology (FCT) under the Grant n. ${ }^{\circ}$ SFRH/BPD/86618/2012; Schools that had participated in this study from the metropolitan area of Lisbon; Center of Psychology Research (CIP) of Department of Psychology of Universidade Autónoma de Lisboa, and Center of Education Research (CIES) of ISPA, Lisbon, Portugal.

\section{REFERENCES}

[1] Munro MJ, Derwing TM, Morton SL.The mutual intelligibility of L2 speech. Studies in second language acquisition 2006; 28(1): 111-131.

https://doi.org/10.1017/S0272263106060049

[2] Gynan SN. Comprehension, irritation, and error hierarchies. Hispania 1985; 68: 160-165. https://doi.org/10.2307/341633

[3] Ensz KY. French attitudes toward typical speech errors of American speakers of French 1982; The Modern Language Journal, 66: 133-139.

[4] White L. Against Comprehensible Input: the Input Hypothesis and the Development of Second-language Competence1. Applied linguistics 1987; 8(2): 95-110.

https://doi.org/10.1093/applin/8.2.95
[5]

Gass SM, Varonis EM. The effect of familiarity on the comprehensibility of nonnative speech. Language Learning 1984; 34: 65-89.

https://doi.org/10.1111/j.1467-1770.1984.tb00996.x

[6] Sadoski M, Goetz ET, Fritz JB. Impact of concreteness on comprehensibility, interest, and memory for text: Implications for dual coding theory and text design. Journal of Educational Psychology 1993; 85(2): 291 https://doi.org/10.1037/0022-0663.85.2.291

[7] Derwing T, Munro M. Accent, intelligibility, and comprehensibility: Evidence from four L1s. Studies in Second Language Acquisition 1997; 19: 1-16. https://doi.org/10.1017/S0272263197001010

[8] Derwing TM, Munro MJ, Thomson RI. A longitudinal study of ESL learners' fluency and comprehensibility development. Applied Linguistics 2008; 29(3): 359-380.

https://doi.org/10.1093/applin/amm041

[9] Kennedy S, Trofimovich P. Intelligibility, comprehensibility, and accentedness of L2 speech: The role of listener experience and semantic context. Canadian Modern Language Review 2008; 64(3): 459-489.

https://doi.org/10.3138/cmlr.64.3.459

[10] Isaacs T, Trofimovich P. Deconstructing comprehensibility. Studies in Second Language Acquisition 2012; 34(3): 475505.

https://doi.org/10.1017/S0272263112000150

[11] Major RC. Identifying a foreign accent in an unfamiliar language. Studies in Second Language Acquisition 2007; 29(4): 539-556. https://doi.org/10.1017/S0272263107070428

[12] Calla MW. The Scalability of degrees of foreign accent (multidimensionality, inter-rater reliability, salience). 1986. Unpublished Doctoral dissertation.

[13] Chen HC. Second language timing patterns and their effects on native listeners. Concentric: Studies in Linguistics 2010; 36(2): 183-212.

[14] Munro MJ, Derwing TM. Processing time, accent, and comprehensibility in the perception of native and foreignaccented speech. Language and speech 1995; 38(3): 289306.

[15] O'Brien MG. L2 Learners' assessments of accentedness, fluency, and comprehensibility of native and nonnative German speech. Language Learning 2014; 64(4): 715-748. https://doi.org/10.1111/lang.12082

[16] Crowther D, Trofimovich $P$, Isaacs $T$, Saito K. Does a speaking task affect second language comprehensibility? The Modern Language Journal 2015; 99(1): 80-95. https://doi.org/10.1111/modl.12185

[17] Flege JE, Frieda EM, Nozawa T. Amount of native-language (L1) use affects the pronunciation of an L2. Journal of Phonetics 1997; 25(2): 169-186.

https://doi.org/10.1006/jpho.1996.0040

[18] Spada N, Lightbown PM. Instruction, first language influence, and developmental readiness in second language acquisition. The Modern Language Journal 1999; 83(1): 1-22. https://doi.org/10.1111/0026-7902.00002

[19] Winke P, Gass S, Myford, C. Raters' L2 background as a potential source of bias in rating oral performance. Language Testing 2013; 30(2): 231-252. https://doi.org/10.1177/0265532212456968

[20] Ferragne E, Pellegrino F. A comparative account of the suprasegmental and rhythmic features of British English dialects. Modelisations pour l'Identification des Langues 2004.

[21] Derwing TM, Rossiter MJ, Munro MJ. Teaching native speakers to listen to foreign-accented speech. Journal of Multilingual and Multicultural Development 2002; 23(4): 245259.

https://doi.org/10.1080/01434630208666468 
[22] Stager CL., Werker JF. Infants listen for more phonetic detail in speech perception than in word-learning tasks. Nature 1997; 388(6640), 381-382. https://doi.org/10.1038/41102

[23] Rubin J. A review of second language listening comprehension research. The modern language journal 1994; 78(2): 199-221.

https://doi.org/10.1111/j.1540-4781.1994.tb02034.x

[24] Chaudron C. Comprehension, comprehensibility, and learning in the second language classroom. Studies in Second Language Acquisition 1985; 7(2): 216-232. https://doi.org/10.1017/S0272263100005386

[25] Swain M, Lapkin S. Problems in output and the cognitive processes they generate: A step towards second language learning. Applied linguistics 1995; 16(3): 371-391. https://doi.org/10.1093/applin/16.3.371

[26] Ünal E., Papafragou A. Production-comprehension asymmetries and the acquisition of evidential morphology. Journal of Memory and Language 2016; 89: 179-199. https://doi.org/10.1016/j.jml.2015.12.001

[27] Benedict $\mathrm{H}$. Early lexical development: comprehension and production. Journal of Child Language 1979; 6(02): 183-200. https://doi.org/10.1017/S0305000900002245

[28] Werker JF, Byers-Heinlein K. Bilingualism in infancy: First steps in perception and comprehension. Trends in cognitive sciences 2008; 12(4): 144-151. https://doi.org/10.1016/j.tics.2008.01.008
[29] Saito K., Webb S., Trofimovich P, Isaacs T. Lexical profiles of comprehensible second language speech. Studies in Second Language Acquisition 2015; 1-25.

[30] Saito Y., Saito K. Differential effects of instruction on the development of second language comprehensibility, word stress, rhythm, and intonation: The case of inexperienced Japanese EFL learners. Language Teaching Research 2016; 1362168816643111. https://doi.org/10.1177/1362168816643111

[31] Carrier K. The social environment of second language listening: Does status play a role in comprehension). The Modern Language Journal 1999; 83(1): 65-79. https://doi.org/10.1111/0026-7902.00006

[32] Hoff E. Interpreting the early language trajectories of children from low-SES and language minority homes: Implications for closing achievement gaps. Developmental Psychology 2013; 49(1): 4-14. https://doi.org/10.1037/a0027238

[33] Walker D, Greenwood C, Hart B, Carta J. Prediction of school outcomes based on early language production and socioeconomic factors. Child Development 1994; 65(2): 606621. https://doi.org/10.2307/1131404

[34] Bowey J. Socioeconomic status differences in preschool phonological sensitivity and first-grade reading achievement. Journal of Educational Psychology 1995; 87(3): 476. https://doi.org/10.1037/0022-0663.87.3.476

Received on 14-01-2017

Accepted on 18-03-2017

Published on 13-04-2017

DOI: https://doi.org/10.12970/2311-1917.2017.05.03

(c) 2017 Figueiredo et al.; Licensee Synergy Publishers.

This is an open access article licensed under the terms of the Creative Commons Attribution Non-Commercial License (http://creativecommons.org/licenses/by-nc/3.0/) which permits unrestricted, non-commercial use, distribution and reproduction in any medium, provided the work is properly cited. 